\title{
La violencia de género en España: apuntes para la erradicación
}

\author{
Violence against women in Spain: \\ notes for erradication
}

Alfonso Toribio del Hierro*

Universidad Carlos III

Recibido: 5/3/2021

Aceptado: 6/4/2021

doi: https://doi.org/10.20318/femeris.2021.6140

\begin{abstract}
Resumen. La violencia de género es un asunto controvertido, acaparador de portadas en los medios de comunicación y un problema social a escala mundial. Su estudio en profundidad para tratar de aportar unas directrices que encaminen a España a eliminar esta violencia es lo que pretende este trabajo. Desde la conceptualización y diferenciación entre sexo y género, desentrañaremos los causantes de este mal endémico y estudiaremos su origen histórico detenidamente. Ofreceremos una perspectiva detallada del caso español, así como una comparativa interpaís para ilustrar más representativamente el fenómeno. Atenderemos específicamente a una serie de prácticas, por la trascendencia y gravedad de las mismas como paradigma de la violencia contra la mujer: la mutilación genital femenina, la prostitución y la trata de seres humanos. Se explicarán las fortalezas y debilidades del caso español en la materia a través del análisis jurídico de la Ley 1/2004 y el Convenio de Estambul. Por último, a modo de conclusiones propositivas instamos a los poderes públicos a llevar a cabo una serie de medidas que consideramos imprescindibles para frenar la violencia machista, desde tener en cuenta y cumplir la agenda propuesta por el movimiento feminista hasta la protección constitucional de las mujeres obligándoles a luchar contra la violencia de género.

Palabras clave: violencia; género; feminismo; violencia de género; sexo; violencia sexual.

Abstract. Gender-based violence is a controversial issue, a grabber of media covers and a social problem on a global scale. Its in-depth study to try to provide guidelines that lead Spain to eliminate this violence, is what this work aims to do. From the conceptualization and differentiation between sex and gender, we will unravel the causes of this endemic problem and we will study its historical origin carefully. We will offer a detailed perspective of the Spanish case, as well as an intercountry comparison to illustrate the phenomenon more representatively. We will specifically attend to a series of practices, due to their importance and gravity as a paradigm of violence against women: female genital mutilation, prostitution and human trafficking. The strengths and weaknesses of the Spanish case on the matter will be explained through the legal analysis of Law $1 / 2004$ and the Istanbul Convention. Finally, by way of pro-
\end{abstract}

*alfonso.toribio@hotmail.com 
positional conclusions, we urge the public powers to carry out a series of measures that we consider essential to stop sexist violence, from taking into account and complying with the agenda proposed by the feminist movement to the constitutional protection of women, forcing them to fight against gender-based violence.

Keywords: violence; gender; feminism; gender-based violence; sex; sexual violence.

\section{Introducción}

La situación y la percepción social de las mujeres en España ha experimentado una rauda y sorprendente transformación desde los años de la Transición. La conquista del acceso masivo de las mujeres jóvenes a la educación superior y a la población activa, la conformación de gobiernos paritarios como el actual, la aprobación de la Ley 1/2004 de Medidas de Protección Integral contra la Violencia de género, la Ley Orgánica 3/2007, de 22 de marzo, para la igualdad efectiva de mujeres y hombres, el anteproyecto de Ley de 27 de mayo de 2011 para la Igualdad de Trato y la No Discriminación (presentada de nuevo recientemente, a 21 de enero de 2021, por el grupo Socialista con opciones de salir adelante), la ratificación por parte del Estado español del Convenio de Estambul (Convenio de Consejo de Europa sobre prevención y lucha contra la violencia contra las mujeres y la violencia doméstica), así como otros avances muy significativos que han conseguido mejorar la calidad de vida de las mujeres, han sido gracias a la aceptación y difusión de importantes valores feministas (Alberdi, 2000, p. 26).

La sensibilización de la sociedad española y el paulatino abandono de la visión de la violencia machista como un problema privado, desde el mediático caso de Ana Orantes en el año $97^{1}$, evidencia el indudable progreso histórico que hemos experimentado. No obstante, el optimismo ha de servir como motivación para el avance, no una excusa para el descanso.

"Por un lado, hay razones para el optimismo cuando el criterio empleado es el de comparar diacrónicamente nuestra situación actual con la de nuestras madres o abuelas; por otro lado, hay razones para el pesimismo cuando comparamos nuestras vidas con las de la otra mitad de la raza humana: los varones." (de Miguel, 2008, p. 2).

Resulta conveniente recordar, como señala Anna G. Jónasdóttir, que incluso en aquellas sociedades con altas cotas de igualdad en el espacio público (como las nórdicas), existen contundentes mecanismos que reproducen la desigualdad sexual que, en último término, generan las cifras de violencia machista más altas de Europa.

Si vivimos en una sociedad igualitaria ¿por qué los varones matan a las mujeres?, ¿por qué las gruesas cifras de malos tratos?, ¿por qué aumenta el tráfico de mujeres y

\footnotetext{
${ }^{1}$ El asesinato de Ana Orantes el 17 de diciembre de 1997 a manos de su ex-marido tras haber expuesto en una entrevista televisiva la violencia a la que llevaba siendo sometida por éste durante más de cuarenta años. Noticia: https:// elpais.com/diario/1997/12/18/espana/882399613_850215.html
} 
niñas con fines de explotación sexual por quince o treinta euros el cliente en nuestras sociedades igualitarias?

La española es una sociedad con un fuerte semblante formal de modernidad, de posmodernidad si se prefiere, en la que aparentemente se han superado las desigualdades sexistas (opinión históricamente recurrente para desacreditar la necesidad presente y futura de la lucha feminista ${ }^{2}$ ) al contar con una legislación y un consenso social para combatirlas, pero que basta echar un vistazo y profundizar mínimamente en los indicadores de igualdad, para descubrir que el camino aún es largo. El cambio ha de ser radical, acompañado de transformaciones estructurales en otros aspectos no tratados en este trabajo (esencialmente legalista), para erradicar la desigualdad, especialmente en su vertiente más salvaje: la violencia y la prostitución. Como apuntan certeramente Celia Amorós y Ana de Miguel, "el cuerpo de las mujeres es el libro abierto en el que se inscriben las reglas de los pactos patriarcales" (Amorós, 2008). "Y en ese libro hoy se escribe la violencia contra sus cuerpos como violencia física y como cuerpos permanentemente expuestos para su alquiler o venta para uso sexual. Cuando se unen ambos tipos de escritura hablamos de violaciones" (de Miguel, 2008, p. 15).

El objetivo aún lejano, la erradicación definitiva de esta lacra, vendrá determinado por la actuación institucional de unos poderes públicos impregnados de literatura feminista que cumplan íntegramente lo ratificado, por lo que se torna imprescindible en esta tarea el análisis de la Ley que guiará su actuación. Dadas estas razones, el objeto de estudio en el que nos centraremos será el análisis de la Ley 1/2004, de 28 de diciembre, sin excluir otras normas mencionadas anteriormente, por su potencial eficacia, su ejemplo histórico incluso a escala internacional en la lucha de la violencia contra la mujer ${ }^{3}$ y por ser el principal texto normativo para combatirla legitimando a los poderes públicos; para estudiar sus efectos y proponer mejoras que refuercen su propósito.

Lo que aquí se pretende es un desafío complejo. Transformar radicalmente el marco legal español para realizar una propuesta que erradique efectivamente la violencia machista, atendiendo a los complejos condicionamientos estructurales y prácticos del caso español (necesidad de consenso parlamentario y apoyos electorales suficientes para su aprobación y entrada en vigor). Las propuestas que incluiremos serán: dotar a las mujeres de protección constitucional por el hecho de serlo (a través de la reforma del artículo 9.2 de la Constitución española), reconocer como violencia machista aspectos aún no reconocidos en la Ley vigente (por el hecho de ser mujer, no de ser o haber sido pareja), contemplar el maltrato económico (por ejemplo a través de la acumulación de faltas por no aportar pensiones estando judicialmente obligado el padre y/o esposo a ello) como una forma de violencia machista castigada por el ordenamiento jurídico, reformar el Código Penal para castigar con penas de prisión a los consumidores de prostitución e incluir a las mujeres prostituidas como víctimas de violencia de género, realizar un registro centralizado a nivel nacional de mujeres y niñas susceptibles de ser víctimas de mutilación

\footnotetext{
${ }^{2}$ Para profundizar sobre el argumentario antifeminista, se recomienda consultar "Faludi, Susan. Reacción. La guerra no declarada contra la mujer moderna, (1991), Barcelona, Anagrama."

${ }^{3}$ La española se trata de la primera Ley Integral contra la violencia de género en Europa.
} 
genital femenina y, por último, eliminar la diferenciación penal entre abuso y agresión sexual trasponiendo el ratificado Convenio de Estambul y vehiculando el consentimiento como criterio diferenciador para considerar el delito de violación sin necesidad de mediar violencia o intimidación. En síntesis, cambiar un conjunto sistémico de aspectos para garantizar la eficacia e íntegro cumplimiento, y no la parcial o mera mejora reformista de la realidad material de las mujeres españolas.

\section{Concepto: ¿qué es el género?}

Antes de hablar sobre la violencia de género y su evolución desde la antigüedad, hemos de preguntarnos qué es el género. Entendemos por género "la construcción social y cultural que define las diferentes características emocionales, afectivas, intelectuales, así como los comportamientos que cada sociedad asigna como propios y naturales de hombres y mujeres." (Berbél, 2004). Esta construcción se entiende como una imposición estructural que, en palabras de los doctores Lorente, perdura al tratarse de unos "patrones de conducta transmitidos de generación en generación, a modo de los imagos o ideas arquetípicas de Jung, que inundan el inconsciente colectivo." (Lorente, 1999, p. 47). Así, el género se define como la ideología detrás de la diferencia de trato a los hombres y a las mujeres, es el tronco primigenio que sustenta la desigualdad en sus distintas variantes de ramaje. A diferencia del sexo, determinado biológicamente, el género se impone a través de la educación y pueden cambiarse los comportamientos asociados al mismo (Berbél, 2004). Parte del problema para buscar una solución a la desigualdad entre mujeres y hombres viene por la falta de claridad en la distinción de estos dos conceptos básicos, capital para comprender la violencia hacia la mujer. No debemos confundir el género con una conducta determinada o una elección en nuestro modo de comportarnos y expresarnos, dado que se trata de una

"construcción sociocultural y no un atributo personal o una conducta particular. Los atributos personales que han sido unidos al género dependen del contexto sociocultural y de la definición de género como una categoría social, de hecho también varía dependiendo de su intersección con otras categorías sociales, tales como la raza o la orientación sexual." (Lorente, 1999, p. 45).

Y es que es el género el que vertebra la estructura de la violencia machista, es la base de la pirámide de la violencia invisible que a su vez es omnipresente en toda su geometría, de manera que:

"El énfasis sobre la diferencia natural y los factores culturales también dieron lugar a la construcción de un "ideal de mujer" que se asignaba a determinadas funciones sociales (las domésticas) y a ciertas conductas (dulzura, paciencia, comprensión...) que eran "casualmente" las idóneas para realizar las tareas que le habían sido previamente asignadas. Así se produce una socialización de las mujeres unida a estos valores y tareas para finalmente acabar 
afirmando que la mujer tiene unos "dotes naturales". En el proceso se esfuma el carácter socialmente construido del género y aparece como natural y biológicamente determinado. En razón del género se asignan unos papeles sociales y esas normas sociales favorecen y crean cierta idea de superioridad en el hombre y expectativas de obediencia en la mujer. Cuando estas expectativas fallan en numerosos casos dan lugar a una situación explosiva de violencia". (Lorente Acosta, 1999, prólogo).

El comienzo de la gestación de esta diferencia de trato lo encontramos lejanamente en la historia, resultando en una desigualdad que tiene de antigua lo mismo que de cierta: ${ }^{4}$

"La educación que se ha dado a lo largo de la historia basada en un tratamiento diferenciado a niños y niñas, esta enseñanza deliberada de la violencia doméstica combinada con la idea de que las mujeres no podían tener derechos humanos, llega a tomar tal auge en la Edad Media que los hombres llegan a tratar a sus mujeres peor que a sus bestias." (Lorente Acosta, 1999, p. 16).

Los mandatos sociales, y legales, acerca de los derechos y privilegios del hombre han legitimado históricamente la dominación y el poder del marido sobre la mujer fomentando la dependencia económica de él y garantizando el uso de la violencia y las amenazas para controlar a aquella. De esta manera, esta construcción social acepta que la mujer no trabaje fuera de casa y vea con malos ojos que un hombre permanezca en el hogar realizando las tareas domésticas (Lorente, 1999, p. 45).

La particularidad de esta opresión, caracterizada por su transversalidad y que condena a la mitad de la humanidad a una eterna minoría de edad, explica al igual que su remoto origen su fuerza y dificultad para derrocarlo, mediante el pacto que, entre la totalidad del sujeto antagónico, el hombre, se ha dado independientemente de su posición social de poder para oprimir a la mujer, ya sea en el ámbito público o en el privado:

"Los caballeros de la Edad Media eran tan asiduos a pegar a sus siervos como a sus esposas y a las mujeres comunes de sus baronías. Los campesinos, viendo la oportunidad de poder que sus amos les otorgaban a cambio de su sumisión al patriarcado, aceptarán esta situación, y así todo hombre, por insignificante que fuera tendría una mujer a su disposición con poder absoluto sobre ella." (Lorente Acosta, 1999, p. 16).

Y es que precisamente a través de esta serie de pactos se conforma un contrato social sexista camuflado en el carácter natural falsamente atribuido al género, encontrando aquí la confusión: en la medida en que la violencia explicada en base al mismo se lleve dando desde hace tantos siglos, no significa que el género sea natural o genético, sino que precisamente la práctica de tantos años lo ha normalizado en nuestras sociedades como si éstas no pudiesen entenderse sin él. Antigüedad no es igual a naturaleza. La esperanza al desolador comienzo de este trabajo reside en esta idea, dado que el género es impuesto

${ }^{4}$ Para profundizar en este tema consultar “ Lerner, G. (1986). La creación del patriarcado. Crítica.” 
y educado, a través de la educación en igualdad podemos abolirlo para erradicar la violencia machista en todas las caras de este poliedro viejo y empolvado que es el patriarcado. De esta manera, la sociedad es el veneno y el antídoto (Lorente Acosta, 1999, p. 39), y a pesar de que este problema continúe asolándonos, existe en una proporción muy diferente a la de antaño, y hace tiempo que se están llevado a cabo significativas reformas en la sociedad, en la justicia y en el trabajo. Quizá debido a una evolución de la mentalidad de las personas derivada de las conquistas logradas por la mujer, que se ve a sí misma y es vista diferentemente pudiendo jugar un distinto papel social, que como el resultado de un reconocimiento explícito de este antiguo problema y de la adopción de medidas activas y positivas encaminadas a abolir esta desigualdad (Lorente, 1999, p. 60).

\section{3. ¿Qué es la violencia de género?}

Siguiendo hasta nuestros días, la legislación vigente española concibe la violencia de género como la violencia que se ejerce sobre éstas (las mujeres) por parte de quienes sean o hayan sido sus cónyuges o de quienes estén o hayan estado ligados a ellas por relaciones similares de afectividad, aun sin convivencia (Art. 1.1; Ley 1/2004), debido a que es en este contexto donde se desarrolla con mayor brutalidad la violencia física contra la mujer.

No obstante, las mujeres parten de una situación de desventaja en todas las sociedades y ser mujer supone el principal indicador de pobreza y exposición a la violencia en el mundo $^{5}$ (UN Women Annual Report 2016-2017, 2017). Al ejercerse violencia contra ellas, en sus distintas formas, no ocurre únicamente en el ámbito la pareja, por lo que debería contemplarse ampliar el estatuto de víctima de violencia de género no sólo a aquellos casos en los que se acredite la mencionada relación de afinidad, sino que si la mujer es discriminada por el simple hecho de serlo, debemos proteger jurídicamente el conjunto de supuestos sociales en donde va a darse esta opresión.

Considerar víctimas de violencia de género en exclusiva a las mujeres maltratadas por sus parejas o ex parejas, implica reducir la violencia machista a la esfera privada y negar su dimensión estructural, histórica y social. La protección existente en la que encajar en el tipo este fenómeno resulta insuficiente, y la respuesta como sociedad a esta lacra que arrastramos desde la antigüedad debe ser completa y total, abarcando todas las aristas de sus manifestaciones, dada su naturaleza compleja y multidisciplinar, si se pretende erradicar por completo y no paliar superficialmente algunos efectos negativos del machismo.

La legislación vigente considera la violencia en este contexto la "física y psicológica, incluidas las agresiones a la libertad sexual, las amenazas, las coacciones o la privación arbitraria de libertad" (Artículo 1.3; Título Preliminar; Ley 1/2004 de Medidas de Protección Integral contra la Violencia de Género). Consideramos necesaria, a su vez,

\footnotetext{
${ }^{5}$ Afirmamos lo referido tras observar los datos de las estadísticas del mencionado informe, como recoge la siguiente noticia: https://www.publico.es/sociedad/feminizacion-pobreza-principal-causa-pobreza-mujer.html
} 
dada la realidad de aquellas mujeres que consiguen hacer frente a su agresor y comenzar una nueva vida como supervivientes de maltrato, la introducción del maltrato económico como un tipo de violencia ejercida por el agresor, muy frecuente en estos contextos, en los que no se procede al pago de pensiones de forma frecuente incluso estando obligado judicialmente a ello.

“En España, el colectivo más afectado por la pobreza es el de las mujeres cabeza de familia (mujeres solas con cargas familiares), las cuales tienen unos ingresos medios inferiores a los de las familias compuestas por dos adultos; que en el caso de las madres solteras, de las separadas y divorciadas, su pobreza se debe principalmente al incumplimiento de los padres en el pago de las pensiones de alimentos a los hijos..." (Pérez del Campo, pp. 58 y 59).

Resultando prácticamente imposible para estas mujeres reconducir su vida y pagando una condena injusta como víctimas, siguen atadas a su maltratador y el riesgo al que quedan expuestas es muy alto. Además, las garantías económicas para superar la violencia de género han de ser suficientes para evitar una de las barreras más frecuentes al denunciar: la dependencia económica al marido siendo éste el único que trabaja fuera del hogar y aporta ingresos, dado que la mujer realiza las tareas domésticas y no percibe remuneración por ello, por lo que depende de él en todos los sentidos, quedando atada a éste y completamente desprotegida.

Esta práctica se encuentra recogida en el artículo 227 CP como abandono de familia, y suele impugnarse por esta vía. Como refuerzo a lo que aquí se argumenta, la Sala Segunda del Tribunal Supremo se ha pronunciado recientemente (STS 239/2021) acerca de esta cuestión, considerando el impago de pensiones como violencia económica y apreciando la imposición de la pena de prisión (por abandono de familia) en lugar de la pena de multa debido a la gravedad del hecho (impago prolongado, durante ocho años en el ejemplo que aquí se expone), y la pena máxima de un año debido también a la extensión del tiempo impagado, sumado a la vulneración inmediata de un acuerdo homologado mediante sentencia.

"existe delito de impago de pensión alimenticia que puede configurarse como una especie de violencia económica, dado que el incumplimiento de esta obligación deja a los propios hijos en un estado de necesidad en el que, ante su corta edad, y carencia de autosuficiencia, necesitan de ese sustento alimenticio del obligado a prestarlo, primero por una obligación moral y natural que tiene el obligado y si ésta no llega lo tendrá que ser por obligación judicial.

Y ello, al punto de que si se produce el incumplimiento del obligado a prestarlos, ello exige al progenitor que los tiene consigo en custodia a llevar a cabo un exceso en su esfuerzo de cuidado y atención hacia los hijos, privándose de atender sus propias necesidades para cubrir las obligaciones que no verifica el obligado a hacerlo. Todo ello determina que podamos denominar a estas conductas como violencia económica cuando se producen impagos de pensiones alimenticias. " (STS 239/2021).

No obstante, la dificultad de apreciar este hecho exceptuando casos especialmente graves como el que se ejemplifica en la sentencia con alzamiento de bienes societario, su- 
mado a la especial situación que sufren la mujer y los hijos como consecuencia del incumplimiento de esta obligación habitualmente por parte del progenitor, exigen un tipo específico considerando esta actuación como violencia de género. Además, debería ampliarse la horquilla penológica para ajustarla a la realidad del hecho en base a su gravedad, con el objetivo de evitar que una de las principales causas de empobrecimiento de las mujeres continúe condenando a éstas a la precariedad.

A su vez, dada la evidencia concluyente acerca del origen de la violencia de género basada en su trasmisión a la infancia, ya sea a través de haber sufrido violencia doméstica en la edad temprana o por haber sido testigo de la violencia ejercida contra la madre o el resto de hermanos, es necesario proteger efectivamente a los menores para evitar las secuelas irreparables en un futuro, especialmente que se conviertan en los maltratadores del mañana. De esta manera, la ampliación del estatuto de víctima de violencia de género debería incluir de forma real y efectiva también a los hijos de la mujer y madre maltratada.

Tras la reforma de 2015 de la Ley 1/2004, se incluye en el artículo 1.2 de la misma la asistencia como víctimas de violencia de género a los hijos menores y menores sujetos a tutela, o guarda y custodia. No obstante, incluyendo a éstos como sujeto principal en el artículo 1.1 (además de facilitar y ampliar el número de mujeres que se quedan fuera de conseguir el estatuto de víctima, desprotegiendo a éstas y a sus hijos menores), el avance en prevención y eficacia en la lucha contra la violencia de género sería más ambicioso.

Como señala el médico y profesor Miguel Lorente:

"Las investigaciones más recientes indican que prácticamente todos los menores inmersos en estas relaciones tormentosas sufren algún tipo de consecuencia en forma de diferentes alteraciones, pero además un 40 por 100 de ellos sufre también violencia física directa consecuencia del maltrato a la mujer, y más de un 30 por 100 padecen alteraciones físicas a largo plazo derivadas de esa violencia." (Lorente, 2004, p. 184). La conformación de la idea de "normalidad" en el menor es clave para entender qué relación establece con las mujeres y, si éste se desenvuelve en un contexto de agresividad o violencia no solo tiene consecuencias a corto y medio plazo para la madre, también se verán afectados todos los miembros de la familia. De esta manera, los niños expuestos a la violencia tenderán a repetir los actos del padre cuando tengan un conflicto en sus relaciones afectivas, mientras que las niñas en su mayoría lo racionalizarán, se sentirán culpables y, unos y otros, normalizarán la violencia en las relaciones de pareja (Lorente, 2004, p. 189).

Al margen de ciertas conductas consideradas de riesgo o comportamientos potencialmente desencadenantes de violencia machista, el factor clave es

\footnotetext{
"haber sido víctimas o testigos de malos tratos durante la infancia o la adolescencia, influyendo tanto en el sentido de victimizar a la mujer como de adoptar una conducta violenta por parte del hombre. No se limita a un momento determinado, sino que se transmite de generación en generación, prolongando y aumentando las consecuencias de las que la sociedad será receptora en todos sus sentidos." (Lorente, 1999, p. 193).
} 
Por lo tanto, para proteger a los menores y cortar de raíz el contagio de la violencia, el primer paso es separar al maltratador de éstos, para que no continúen percibiendo el daño y, especialmente, no se vean infectados y normalicen el maltrato en las relaciones interpersonales. Para que esta estrategia sea efectiva, y dada la tendencia de muchos jueces no liberados del "prejuicio patriarcal jerarquizante de la familia" (Pérez del Campo, 1995, p. 163), si considerásemos a los hijos como indudables víctimas de violencia machista les será más fácil tomar decisiones relativas a la custodia, se les protegerá debidamente del influjo del maltrato y no primaría tanto el orden "naturalmente impuesto" de la familia tradicional a la hora de ponderar, no existiendo un derecho natural sobre los hijos como posesión, menos aún si existe ese influjo completamente perjudicial para ellos y para nuestra sociedad en conjunto.

De esta manera, concebimos la violencia de género como aquella violencia física, psicológica, sexual y económica ejercida sobre las mujeres y los hijos de éstas por el hecho de ser mujeres, independientemente de la relación afectivo-sexual existente entre víctima y agresor, pero sin perder de vista que la mayoría de casos de este tipo de agresiones se dan en el seno de la pareja.

\section{Breve intrahistoria de España}

Proyectando la realidad patria a través de los datos del Instituto Nacional de Estadística en su publicación "Mujeres y hombres en España”, esbozaremos mediante algunos de sus indicadores un breve relato sobre el patriarcado nacional teniendo 2004 como fecha de referencia, para comprobar si la Ley 1/2004 tuvo efectos significativos o no, si las mejoras o retrocesos son imputables a ella, así como para identificar los sectores a tener en cuenta para avanzar en igualdad y situar nuestro país en un contexto internacional para, en caso de ser pertinente, promover la importación de fórmulas jurídicas extranjeras eficaces en esta materia, valorar las presentes e introducir propuestas originales.

Sin perder de vista el lastre que arrastran las políticas encaminadas a la igualdad entre mujeres y hombres en nuestro país, trataremos de superar el recurrente fallo a la hora de implementarlas cuando se sacrifica la calidad de aquellas por las cifras, en lugar de cuidar el contenido y la efectividad de los programas. Sirven de poco aquéllas si no van acompañadas de recursos, estructuras y personas adecuadas con una firme convicción ideológica acorde con el programa a desarrollar; condiciones necesarias para posibilitar viablemente su ejercicio; o cuando se antepone "la espectacularidad de lo accesorio", obviando la capital importancia de la finalidad (Pérez del Campo, 1995, p. 149). De esta manera, tendremos en cuenta los datos como simples indicadores que demuestran que aún queda mucho trabajo por hacer, tratando de mirar más allá de las tablas y los gráficos y preguntándonos por qué, por ejemplo, el número de denuncias es tan bajo, por qué matan a mujeres que habían denunciado y cómo podemos mejorar la eficacia de las instituciones para proteger a tantas que lo necesitan. 
Como esbozo general, la población en riesgo de pobreza relativa en España es mayor entre las mujeres en todos los niveles ${ }^{6}$, con respecto a la cúspide de la violencia machista, desde 2004 han disminuido sensiblemente los asesinatos machistas, si bien hay que disponer del margen suficiente para apreciar el impacto en la sociedad de la ley y hasta 2010 no comenzó a disminuir, también hemos de tener en cuenta que los problemas existentes de acceso a la justicia (como el miedo a denunciar) explican que una disminución en esta gráfica no se deba necesariamente a una disminución del machismo en nuestra sociedad atribuible a esta ley. En base a esta gráfica y en líneas generales, la Ley 1/2004 se ha mostrado ligeramente eficaz, si bien dista bastante de convertirse en un instrumento para erradicar la misoginia y el machismo de la sociedad española.

Número de víctimas mortales por violencia de género. 1999-2019

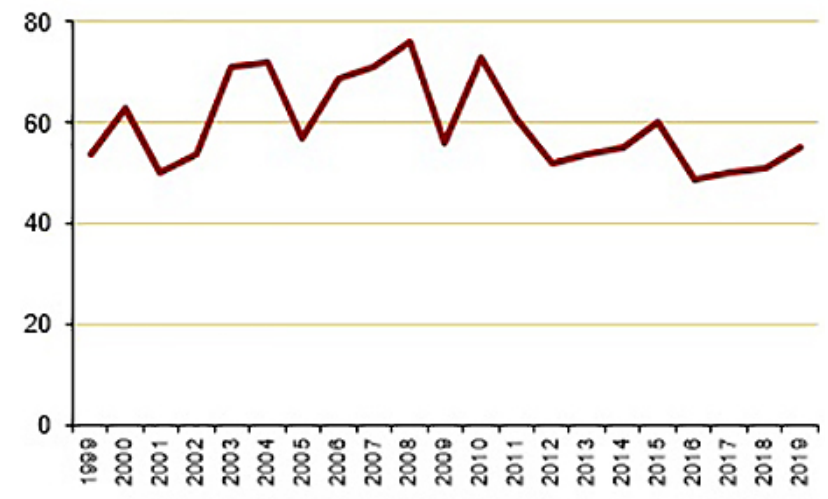

Nota: se incluyen aquellos casos en los que el agresor es el cónyuge, excónyuge. compañero sentimental, excompañero sentimental, novio o exnovio.

Fuente: 1899-2005: Instituto de la Mujer a partir de noticias de prensa y de datos del Ministerio del Interior. A partir de 2000 datos de la Delegación del Gobierno para la Violencia de Género

Figura 1.

El número de horas dedicadas al trabajo remunerado y no remunerado (cuidado $\mathrm{y}$ educación de sus hijos o nietos, cocinar y realizar tareas domesticas, cuidado de familiares ancianos o con alguna discapacidad, hacer un curso o formación, actividades deportivas, culturales o de ocio, políticas o sindicales, actividades de voluntariado o caritativas) revela diferencias aún persistentes que ilustran a la perfección la insuficiencia de lo logrado. Mientras que el número de horas del empleo remunerado dista en menos de 6 puntos, la diferencia del tiempo dedicado entre hombres y mujeres del trabajo no remunerado es de

${ }^{6}$ Fuente: INE.es. Salarios, Ingresos, Cohesión Social. Población en riesgo de pobreza relativa según situación laboral y periodo. España, UE-27 y UE-28 (población de 16 a 64 años).

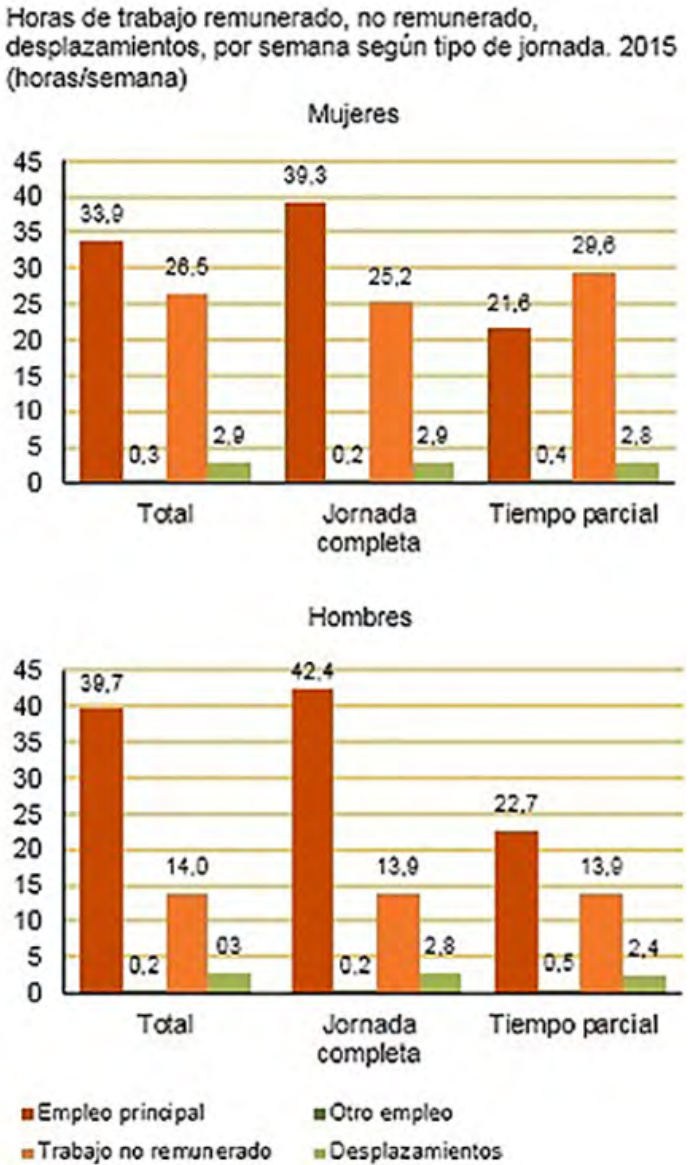

Nota: Encuesta realizada a personas ocupadas

Fuente: Encuesta Nacional de Condiciones de Trabajo. o" EWCS. 2015. Instituto Nacional de Seguridad e Higiene en el Trabajo

Figura 2. 
12.5 horas a la semana. Cuando introducimos diferencias entre la existencia o no de hijos y si tiene pareja (gráfico adjunto), las diferencias son abismales. Casi siempre es más del doble el número de horas dedicadas por las mujeres españolas al trabajo no remunerado, pero cuando éstas tienen hijos la cifra se dispara. Observamos un escalón abismal que alcanza el equivalente a una jornada completa ( 40 horas semanales), mientras que en los hombres ese trabajo a lo sumo alcanza las 20 horas a la semana. Con razón han defendido históricamente el movimiento feminista la importancia de la división sexual del trabajo, el expolio en términos económicos que se les debe a las mujeres es incalculable. Porque "una población de mujeres genérica y enteramente liberada de la servidumbre doméstica, quiebra en su base la actual injusta estructuración de la sociedad." (Pérez del Campo, 1995, p. 153). El reparto equitativo de las tareas del hogar y los cuidados debe ser una prioridad en la coeducación y en los objetivos marcados por la Ley para combatir la violencia machista, dado que aunque puedan verse como asuntos separados, uno es un mandato básico del género y el otro la consecuencia más brutal y violenta del mismo. Además, liberar a las mujeres del trabajo doméstico supone también dotarlas de autonomía económica, principal paso para salir de una situación de

Tasa de graduados en ciencias, matemáticas, informática, ingeniería, industria y construcción. 2018 maltrato por la existencia de medios materiales para rehacer una vida. Es evidente que la Ley $1 / 2004$ no ha logrado superar este aspecto y ha de ser una prioridad acudir a la raíz del problema para curar en menos generaciones de las estimadas la desigualdad entre sexos.

Síntoma de no estar sanada de esta dolencia, España aún no ha superado tampoco la brecha en las carreras universitarias asociadas a oficios tradicionalmente desempeñados por hombres, situándose en niveles inferiores a los europeos para las mujeres. El mandato del gé-

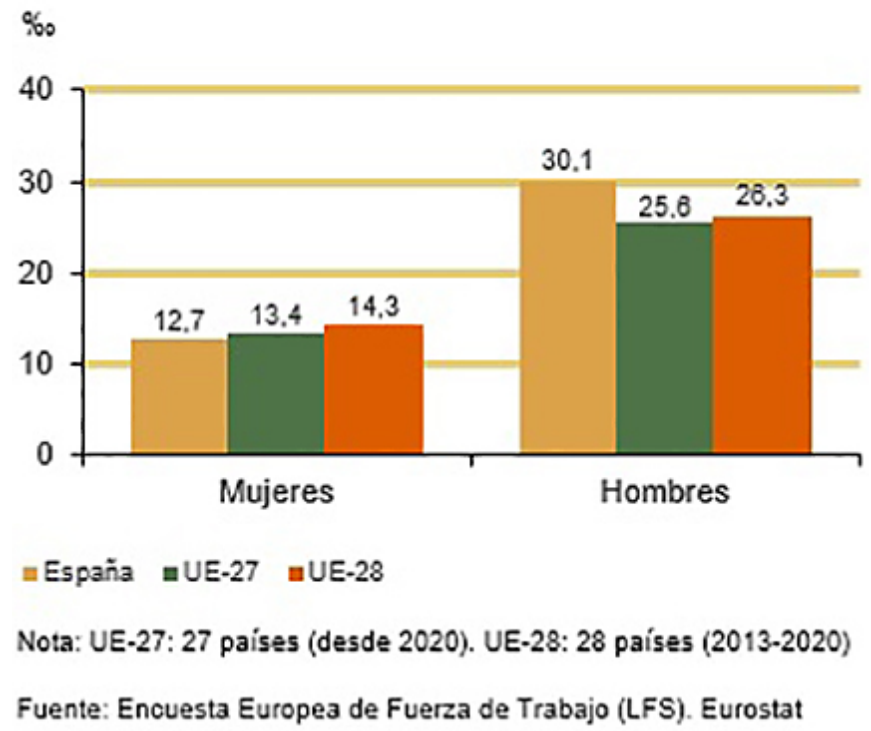

Figura 3. nero sigue presente en nuestra sociedad y estamos lejos de abolirlo, hemos de avanzar hasta que por lo menos consigamos el mismo número de licenciadas en ciencias, matemáticas, informática, ingeniería, industria y construcción, que de licenciados. Siendo otro aspecto relevante que observar como indicador de los efectos del género en la conformación de futuros distintos para las mujeres y los hombres en España.

En su inmensa mayoría, los partidos políticos tienen una sobrerrepresentación de varones en sus cargos ejecutivos. En materia de género, la sociedad española no se encuentra debidamente representada, existiendo ligeramente más mujeres que hombres (algo más de 23 millones 700 mil frente a los 23 millones 100 mil varones, según datos del INE). 
El poder político peca de cierta discriminación que ya se intenta paliar para tratar de asegurar a las mujeres el espacio que les corresponde en el ejercicio del mismo, pero que aún no se haya logrado una igualdad efectiva en este ámbito es representativo del lugar en el que nos encontramos y, en consonancia con el resto de datos y pese a las mejoras acaecidas, las cifras invitan a la esperanza por seguir luchando.

Frente al tópico (ya aludido en la introducción) recurrente en la historia del feminismo sobre su necesidad en el pasado y su impertinencia en el presente por ser "extremista" y demás calificativos peyorativos, reivindicamos que la realidad española exige una lucha feminista fuerte en el presente y fu-

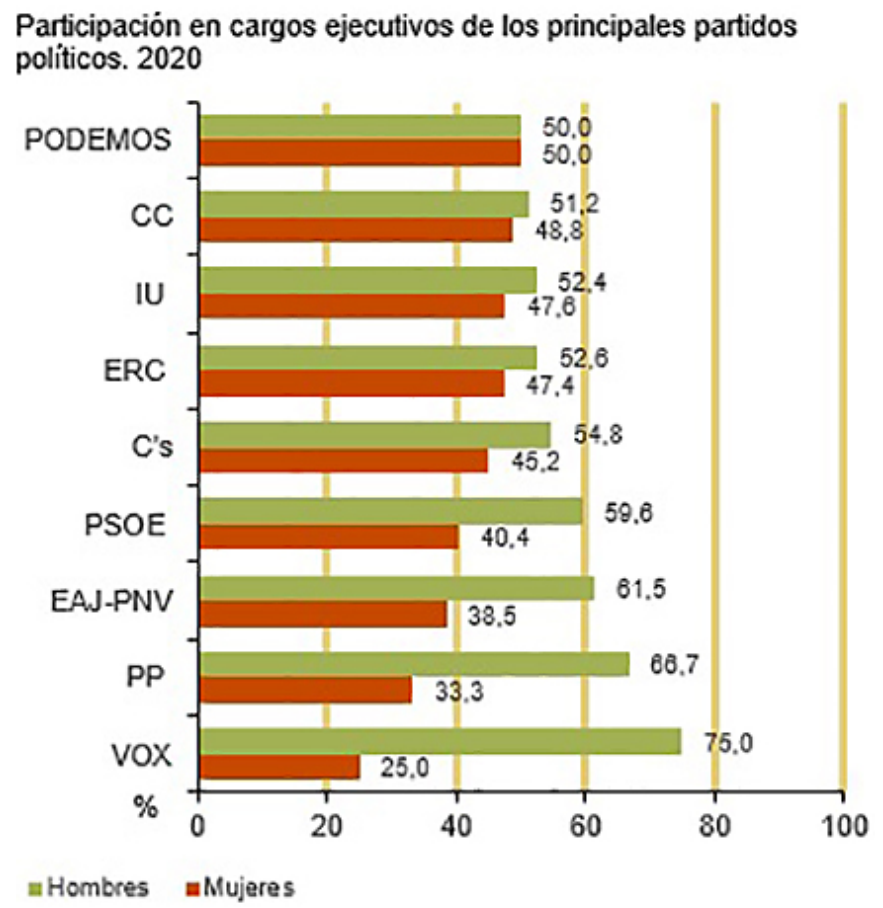

Fuente: Elaboración del Instituto de la Mujer y para la Igualdad de Oportunidades a partir de los datos publicados en la web de cada uno de los partidos políticos

Figura 4. turo (por lo menos cercano) hasta convertir estos indicadores de desigualdad tomados como ejemplo y otras referencias sociológicas en irrelevantes, por lo menos, para los estudios de género. Esta batalla ha de ser también obra conjunta del resto de la ciudadanía, a la que este trabajo pretende sumar humildemente, puesto que solo con la voluntad política conjunta y democrática conseguiremos revertir esta situación.

\section{La violencia de género en el mundo: perspectiva comparada}

La magnitud de esta problemática obliga a tener en cuenta la realidad de las mujeres más allá de las fronteras nacionales. Según datos de Naciones Unidas, la violencia de género se da como mínimo en 1 de cada 3 mujeres en el mundo (UNFPA, 2020), esto teniendo en cuenta la definición institucionalizada de qué se entiende por este tipo de violencia y los datos que consiguen recabar tanto las autoridades estatales como organismos internacionales, que en muchos lugares del globo alcanzan un porcentaje ínfimo de la realidad.

Tanto para entender su trascendencia como para buscar soluciones en otros contextos, la perspectiva comparada es necesaria incluso en un estudio de caso nacional dado que el problema de la aceptación de la violencia de género supera los estereotipos culturales, las clases sociales y no se supera con una mayor formación académica (Burgués, Oliver, Redondo, y Serrano, 2006) además de afectar a mujeres de todos los países, clases sociales, culturas y edades. Así, nos asomaremos a la realidad de la mujer en distintos 
países, veremos qué dice el derecho internacional que vincula a España (especialmente el Convenio de Estambul), expondremos qué prácticas funcionan en otros países y serían susceptibles de implantación en nuestro país, así como reconocer aquello en lo que el Estado español es pionero y aplica correcta y eficazmente.

\subsection{La mutilación genital femenina}

Una de las prácticas recurrentes más vejatorias para los derechos de las mujeres y las niñas en el mundo, especialmente vulnerables, es la mutilación genital femenina (en adelante MGF). Estos procedimientos se practican generalmente entre la lactancia y la adolescencia, y en algunos casos en la edad adulta. Se calcula que cada año más de 3 millones de niñas corren el riesgo de sufrir MGF (OMS, 2020) y que más de 200 millones de mujeres y niñas vivas actualmente han sido objeto de esta práctica según datos disponibles en 30 países (UNICEF, 2016). Entre aquellos países en los que prevalece este tipo de mutilación varía entre los grupos étnicos de alrededor de 30 países del África Subsahariana y en algunos de Oriente Medio y Asia, en el que se realiza desde tiempos ancestrales como rito de paso y constituye un elemento socializador indispensable para la socialización de las niñas (Delegación del Gobierno para la Violencia de Género, 2020).

El alto peso demográfico de la población española proveniente de aquellos contextos, con tasas de masculinidad altas y muy propicias a los reagrupamientos familiares así como a la elevada natalidad, aumenta el riesgo de las niñas de ser víctimas de MGF. Como recoge el último estudio de MGF en España, realizado por la Delegación del Gobierno para la Violencia de Género, la MGF es una realidad social en España pese a su persecución judicial, concentrándose en la referida exportación de la práctica que ciertos grupos étnicos realizan desde sus países de origen.

“Según el 'Joint Shadow Report - Spain', se destaca que no existe un registro nacional que centralice el número de casos de mujeres y niñas afectadas por la MGF en España y debería ser una obligación del Gobierno proveer este registro de carácter nacional involucrando a las administraciones públicas a distintos niveles (acorde al artículo 11 del Convenio de Estambul)" (Delegación del Gobierno para la Violencia de Género, 2020).

La obligatoriedad de este registro consiste en la recopilación de datos a intervalos regulares, no implicando necesariamente la creación de un registro estable. Además, el Gobierno español se ha mostrado reacio a implementar esta directriz futura como expresa en el mismo 'Joint Shadow Report - Spain', dado que delimitar a población proveniente de ciertos países podría suponer una causa de discriminación. Más que una excusa para no crear un registro estable que permita erradicar eficazmente este tipo de prácticas hacia las mujeres y niñas, la observación realizada por el gobierno español ha de verse como un reto. Así, la creación de este registro ha de estar planteada en términos que eviten cualquier tipo de estigma por motivos de origen o procedencia, dado que es un primer paso imprescindible para la actuación de los poderes públicos españoles en esta lucha. No obstante, si tenemos en cuenta el número de menores de 14 años provenientes de aque- 
llas zonas en las que es habitual la ablación del clítoris, podemos cifrar en torno a 18.000 las niñas en riesgo de ser mutiladas en España (Baena Garrido, 2020). Por ello, tanto las que han sido víctimas como la población en riesgo de serlo deberá ser una información esencial y una condición necesaria a disposición del Estado español de cara a la actuación preventiva y la evitación de este tipo de crímenes.

\subsection{Prostitución y trata de seres humanos}

La trata de personas, especialmente de mujeres y niñas con fines de explotación sexual (íntimamente ligada a la prostitución, dado que el tráfico es una consecuencia de la oferta y la demanda del mercado de la prostitución (Díez Gutierrez, 2009)), representa una de las caras más violentas de la desigualdad entre sexos de la que España no es capaz de librarse pese a sus esfuerzos en igualdad, dado que constituye el tercer país del mundo que más prostitución demanda (Hernández Velasco, 2019) según datos de la ONU, siendo uno de los principales destinos del tráfico de mujeres y un punto estratégico en el tránsito (UNODC, 2010). Naciones Unidas cifra en torno a 350.000 las mujeres prostituidas en España, de las cuales, se calcula que entre el 80 y el 90\% son migrantes (TAMPEP, 2009). A su vez, el nuestro es el segundo país de Europa que cuenta con más burdeles, y es que Naciones Unidas advierte que el 39\% de los varones españoles ha pagado en alguna ocasión por mantener relaciones sexuales. El negocio de la prostitución mueve alrededor de 108.000 millones de dólares anuales internacionalmente, constituyendo el segundo que más cantidad de dinero maneja a nivel mundial después de la droga. En España, esta actividad supone el 0.35\% del PIB (INE, 2018), es decir, 4.100 millones de euros en estimación para el año 2018. Si las cifras oficiales son alarmantes, los expertos apuntan que se infravalora la realidad al ser demasiado precavidos con ellas, así como para tener en cuanta a las menores de edad que sufren esta violencia. ${ }^{7}$

La dificultad punitiva que plantea la erradicación de esta práctica se ejemplifica de manera representativa con el número de causas enjuiciadas por proxenetismo que recoge la Fiscalía General del Estado, siendo estas tan solo 103 en el año 2017. España solo castiga ciertas formas de proxenetismo y además de la dificultad en el planteamiento de la prueba al tratarse habitualmente de organizaciones transnacionales, se suma la necesidad de probar la vulnerabilidad de la víctima, siendo absolutamente indispensable el testimonio de esta que, normalmente, debido a la situación de miedo y extrema indefensión a la que se ve sometida, no se presta a facilitar. Para combatir esta realidad especialmente dañina en nuestro país hemos de comenzar por incorporar un elemento del caso boliviano: la consideración de la trata de seres humanos como delito de lesa humanidad sin prescripción debido a su gravedad, para facilitar así el enjuiciamiento de estos casos especialmente difíciles en la recabación de pruebas, así como la penalización al pagador,

\footnotetext{
${ }^{7}$ Declaraciones del profesor investigador de la Universidad Pontifica de Comillas Jorge Urroz durante las jornadas "Visibilizando a las víctimas de trata" el 23 de septiembre de 2016. Consultar en: https://ecodiario.eleconomista.es/ sociedad/noticias/7845621/09/16/Las-cifras-de-la-explotacion-sexual-en-Espana-40000-mujeres-la-sufren-.html
} 
considerado un cooperador necesario para que este tipo de violencia contra las mujeres persista. ${ }^{8}$ Siguiendo el ejemplo de Suecia que desde 1999 establece penas de cárcel para los demandantes de prostitución y que posteriormente países como Noruega han implantado, estas medidas junto con la consideración de las prostitutas como víctimas de violencia de género han demostrado ser eficaces, reduciendo significativamente el número de mujeres prostituidas ${ }^{9}$.

Por lo que, dado que la erradicación de la violencia machista pasa necesariamente por la abolición de la prostitución puesto que ésta se encuentra íntimamente ligada a la trata de seres humanos y constituye un atentado contra la igualdad de género, consideramos necesaria la punición con penas de cárcel para los clientes de prostitución, así como la consideración de mujeres prostituidas como indudables víctimas de violencia de género que puedan acogerse a la protección que el Estado brinda a éstas. El Estado español, así, debe abandonar la ambigua situación actual de alegalidad en materia de prostitución y apostar por formas abolicionistas del modelo nórdico para avanzar en materia de igualdad.

\subsection{Normativa internacional: el Convenio de Estambul}

La amplia colección de instrumentos que el derecho internacional presenta para la lucha en la eliminación de la violencia contra la mujer ha sido elaborada en la inmensa mayoría de Organizaciones internacionales universales y regionales. Estas herramientas que superan las barreras nacionales son (Delegación del Gobierno para la Violencia de Género, 2020):

- La Declaración Universal de los Derechos Humanos de 1948 y el Pacto Internacional de Derechos Económicos Sociales y Culturales y el Pacto de Derechos Civiles y Políticos de 16 de diciembre de 1966, ambos redactados por la Organización de Naciones Unidas, organismo clave en esta labor.

- La Convención sobre eliminación de todas las formas de violencia sobre la mujer (CEDAW) de 18 de diciembre de 1979.

- III Conferencia Mundial sobre la Mujer, celebrada en Nairobi en 1985.

- IV Conferencia Mundial sobre la Mujer, celebrada en Beijing en 1995.

- Comisión de la Condición Jurídica y Social de la Mujer (CSW).

- En el ámbito europeo, el Consejo de Europa destaca por esta labor con el Convenio Europeo para la Protección de los Derechos Humanos y las Libertades Fundamentales, aprobado en Roma el 4 de noviembre de 1950. Labor que culminaría con el Convenio sobre prevención y lucha contra la violencia contra las mujeres

\footnotetext{
${ }^{8}$ En opinión de Beatriz Sánchez Álvarez, fiscal adscrita al Fiscal de la Sala de Extranjería. Consultar en: https://www. elmundo.es/espana/2019/02/04/5c588ed421efa079228b45a5.html

${ }^{9}$ Según datos del Instituto sueco, en diez años desde su entrada en vigor, esta ley ha conseguido reducir la cifra de compradores de prostitución desde el 13,6\% hasta situarla en menos del 8\% de la población de Suecia. Consultar en: https://elpais.com/internacional/2016/04/07/actualidad/1460050306_463588.html
} 
y la violencia doméstica, de 11 de mayo de 2011, conocido como Convenio de Estambul.

- La Carta de los Derechos Fundamentales de la Unión Europea consagra en su artículo 23 la igualdad entre mujeres y hombres como valor fundamental.

- El Parlamento Europeo sintetiza en la Resolución del Parlamento Europeo sobre la Violación de los Derechos de las Mujeres el 14 de abril de 1997 las resoluciones elaboradas sobre agresiones a mujeres, pornografía, violaciones de libertades y derechos fundamentales y trata de seres humanos. El 26 de noviembre de 2009 publica la Resolución sobre la eliminación de la violencia contra la mujer, instando a los Estados miembros a emprender acciones para combatirla.

Además de otros desarrollos normativos sobre cuestiones específicas de violencia contra la mujer, como por ejemplo la Directiva 2002/73 de 23 de septiembre de 2002 del Parlamento y del Consejo, sobre acoso sexual y la mutilación genital femenina.

Todos estos textos han sido ratificados por el Estado español, y a pesar de ello seguimos encontrando aquellos problemas que estas normas pretenden extinguir, por lo que una vez más la calidad de la implementación demuestra mayor importancia que el número de normas que se ratifiquen para conseguir un cumplimiento efectivo de los textos legales.

Entre estos textos destacaremos el Convenio de Estambul (Convenio del Consejo de Europa sobre prevención y lucha contra la violencia contra las mujeres y la violencia doméstica) de 2011 ratificado por España en 2014 y entrando en vigor con su publicación en el Boletín Oficial del Estado el 6 de junio del mismo año. Nos centraremos en esta norma vinculante para España por el incumplimiento sistemático de un aspecto fundamental de la misma, que el movimiento feminista patrio lleva reivindicando durante décadas (además de Amnistía Internacional ${ }^{10}$ ), y que adquirió especial relevancia recientemente por el mediático caso de "La Manada"11. Nos referimos a la distinción de los tipos penales de abuso y agresión sexual (Ley Orgánica 10/1995, 1995, arts. 181 y 178, respectivamente), en los cuales se emplea la concurrencia de violencia o intimidación para discernir entre un tipo penal u otro, cuando el ratificado Convenio de Estambul, en su artículo 36, menciona exclusivamente el consentimiento como criterio a tener en cuenta para hablar de violencia sexual (incluida la violación, como reza el título del citado artículo). De esta manera, el Estado español está incumpliendo un Convenio ratificado, por lo que esta reforma es una exigencia para el Derecho nacional. Puesto que el consentimiento ya es tenido en cuenta a la hora de valorar este tipo de delitos, se trata de "redimensionar su valencia" dejando a un lado otros criterios como la violencia o la intimidación (Acale Sánchez, 2020, p. 36). A su vez, el Tribunal Supremo apunta en la STS 344/2019, de 4 de julio de 2019, que para

\footnotetext{
${ }^{10}$ https://www.amnesty.org/es/latest/campaigns/2018/04/eu-sex-without-consent-is-rape/

${ }^{11}$ Un caso de violación grupal de cinco hombres a una joven de 18 años en las fiestas de San Fermín, muy polémico en la sociedad española en torno a la diferenciación penal entre abuso y agresión sexual. Inicialmente los tribunales navarros sentenciaron el caso como un abuso sexual, el pleito concluyó con la sentencia condenatoria de violación por parte del Tribunal Supremo. Es de destacar la masiva movilización que el movimiento feminista español consiguió en las calles expresando su rechazo a las sentencias iniciales y demostrando su desacuerdo con la concurrencia de violencia o intimidación para que se dé una violación, en la concurrencia o no de consentimiento.
} 
valorar el consentimiento no se trata únicamente que la víctima haya expresado que no, sino que el silencio es una forma de comunicación válida en este contexto sórdido y crudo y "puede ser interpretado como un rechazo". Proponemos, pues, que se refundan los tipos penales de agresión y abuso sexual, y todo acto sexual sin consentimiento se enmarque como el mismo delito: una violación.

Por este motivo, el anteproyecto de ley revisado por el Consejo Fiscal en los momentos de redacción de este trabajo (Anteproyecto de Ley Orgánica de Garantía Integral de la Libertad Sexual), que propone llevar a cabo esta reforma del Código Penal en su artículo $178^{12}$ además de elevar a rango de Ley Orgánica el contenido ratificado en 2014 con el Convenio de Estambul, es muy necesario y esperemos que siga adelante y esta propuesta se materialice, debiendo tenerse en consideración la gravedad del ataque con el ajuste de las penas mediante un listado de circunstancias extraordinarias para ampliar el injusto en la agresión sexual (Acale Sánchez, 2020, p. 54), con la esperanza de que pronto el abuso y la agresión sexual se refundan en un único tipo penal, el de agresión sexual, en torno a la idea de consentimiento, y se consiga así avanzar en el cumplimiento íntegro del Convenio de Estambul.

\subsection{La Ley española contra la violencia de género (1/2004) en contexto}

Las leyes de los Estados en materia de igualdad podemos dividirlas en función de la velocidad con la que se esté atajando el problema de la desigualdad basada en el sexo (Marín de Espinosa Ceballos, 2017). Por un lado, tenemos aquellas que se limitan a mencionar el feminicidio (ej. Chile u Honduras), por lo que estos Estados deberían desarrollar una normativa específica en materia de violencia de género, posteriormente tendríamos aquellos estados que, contando con una normativa específica para combatir la violencia de género, solo entienden ésta en el ámbito de la pareja (como es el caso de España). Estos países tienen leyes de primera generación, destinadas a proteger a la familia de la violencia doméstica más que a las mujeres específicamente. Finalmente, nos encontramos con países que tienen verdaderas leyes contra la violencia de género porque incluyen a todas las mujeres que pueden sufrirla, no sólo la pareja. Estas leyes no olvidan que existen otras víctimas del machismo (hijas, hermanas, madres, vecinas, compañeras de trabajo, etcétera) y otros contextos además del doméstico en el que se vulneran los derechos de las mujeres (profesional, educativo, en el ocio...). Es decir, que estas leyes no protegen a las mujeres de todos los actos de violencia en circunstancias de desigualdad estructural ni contemplan todos los tipos de agresiones para someterla. Por este motivo, pese a lo positivo de lo conseguido hasta el momento, consideramos la española una ley insuficiente e incompleta que solo es capaz de dar una respuesta parcial al fenómeno multidisciplinar de la violencia de género. De esta manera, España tiene que avanzar siguiendo las reco-

\footnotetext{
${ }^{12}$ El citado artículo reza así: 1 . Será castigado con la pena de prisión de uno a cuatro años, como reo de agresión sexual, el que realice cualquier acto que atente contra la libertad sexual de otra persona sin su consentimiento. Se entenderá que no existe consentimiento cuando la víctima no haya manifestado libremente por actos exteriores, concluyentes e inequívocos conforme a las circunstancias concurrentes, su voluntad expresa de participar en el acto".
} 
mendaciones para conseguir una ley de segunda generación completa contra la violencia machista que contemple todas las formas de violencia de género, para aspirar a alcanzar cotas más altas de igualdad entre mujeres y hombres.

En líneas generales y como colofón, España indudablemente se sitúa en una posición ventajosa en igualdad de género en comparación con la mayoría de países del mundo ${ }^{13}$, no obstante, el formalismo legal que observamos internamente también se da con respecto las normas internacionales: España ratifica todo tratado contra la de violencia de género a la par que incumple ciertas prerrogativas esenciales para la igualdad y parecen no ser suficientes para sepultar el machismo, puesto que las cifras continúan siendo alarmantes en esenciales indicadores de desigualdad.

\section{De la lucha y la esperanza: hacia la constitucionalización}

El estado actual de los derechos la mujer en España, y especialmente en el mundo, invita al pesimismo. No obstante, las conquistas logradas y la progresiva aceptación del feminismo en la sociedad española auguran un futuro en el que la posibilidad de la erradicación no sea una quimera. De las diversas formas que esta violencia presenta y las dificultades que este poliédrico problema plantea, la única conclusión clara es que para acabar con la violencia de género y el machismo es necesario continuar la lucha.

Es por ello que la conclusión de la progresiva aceptación de la lucha feminista en la sociedad española ${ }^{14}$, materializada en el Pacto de Estado contra la Violencia de Género de 2017, ha de ser la protección constitucional de esta labor a través de la reforma del artículo 9.2 CE para incluir expresamente la igualdad de género como labor de los poderes públicos. Blindar, así, el feminismo en la esencia misma del Estado español es una tarea pendiente en nuestro país, dado que un esfuerzo tan grande no puede depender exclusivamente del color político momentáneo de aquél que ostente el Gobierno, y la actuación encaminada a combatir el sexismo ha de ser permanente $y$, de incumplirse, considerarse contraria a la Carta Magna del Estado.

Lejos de pretender solucionar los problemas del sexo femenino a través de una política simbólica como puede parecer la constitucionalización de la lucha contra la violencia de género, el único símbolo que pretendemos exhibir es el de la materialidad de las políticas propuestas en este trabajo que afectan directamente a los intereses y necesidades de las mujeres españolas y el refuerzo a la legitimidad del movimiento feminista. De igual manera, constitucionalizar la protección a la mujer supone aumentar el sistema de garantías para asegurar la no vulneración de sus derechos y reforzar la acción multinivel en el tratamiento del problema.

${ }^{13}$ Concretamente, España es el octavo país del mundo según "The Global Gender Gap Report 2020". Consultar: https://amecopress.net/Espana-octavo-pais-del-mundo-en-igualdad-de-genero

${ }^{14}$ Según la nota informativa del Barómetro de febrero de 2020 del CIS, el 93,3\% de los españoles cree que la violencia de género es un problema preocupante. Además, un 71,3\% de los encuestados considera que la actual ley de violencia de género no es suficiente y "habría que hacer más cosas". 
Como recordatorio constante en la acción de gobierno, la importancia de esta propuesta es tan grande como su dificultad de llevarla a cabo, dado que sería necesario el procedimiento de reforma "agravado" (art. $168 \mathrm{CE}$ ) con la correspondiente mayoría de dos tercios en el Congreso y Senado, con las exigencias y garantías de consenso que ello conlleva, respetando los procedimientos formales y límites materiales. No obstante, esta medida debería ser tenida en cuenta en la siguiente ocasión de reforma del texto constitucional y aprovechar la circunstancia para llevarla a cabo si se quiere atajar el problema de la violencia machista, cuestión urgente para los poderes públicos, dado que así lo considera la sociedad española. Este consenso social que demanda el fin de la violencia contra la mujer, ha de visibilizarse en el seno de las instituciones guiando a los actores políticos a consensuar un acuerdo permanente que materialice el pacto social ya conseguido entre la ciudadanía, y la mejor forma de hacerlo es con la constitucionalización expresa, acto que ayudaría a definir la posición jurídica de las mujeres con los poderes públicos (Torres Díaz, 2013, p. 28).

Con el mismo propósito de carácter sustancial y alejado de la crítica al simbolismo que esta reforma podría suponer, el avance que la protección constitucional supondría para las mujeres permitiría escalar en los indicadores de democracia, dado que un país en el que la mitad de la población vive con miedo de ser agredida sexualmente ${ }^{15}$, que solo condena entre un 10 y un 15\% de este tipo de violencia (INE, 2019), el estado de impunidad que casos como el de "La Manada" demostraron al exponer que "violar sale barato" en España, es algo que una democracia avanzada no puede permitirse. Porque a pesar de tener una buena ley, y que cuando se castigue a los culpables se haga adecuadamente, los fallos de nuestro Derecho penal contemporáneo son sobre todo para con la víctima, dado que aquél "cumple más o menos bien su papel respecto al delincuente, pero que no cumple ni mínimamente su papel respecto a la víctima" (Bernistain Ipiña, 2000, p. 60). Si esto ocurre generalmente, más aún lo es para los casos en los que es víctima de SAM (Síndrome de Agresión a la Mujer ${ }^{16}$, faltando las "pretensiones de la victimología” para que las víctimas sean atendidas humanamente "antes, durante y después del proceso penal con el fin de evitar una segunda victimización” (Bernistain Ipiña, 2000, p. 60).

Por todo ello, el conjunto de propuestas planteadas en este trabajo deberá apuntar a conseguir la constitucionalización de esta violencia como garantía de correcta actuación de todo el aparato del Estado, para que la acción encaminada a hacer de la violencia de género un asunto pasado sea total, desde todas las aristas que este complejo problema abarca y requiere para su erradicación.

15 “El 83\% de las mujeres españolas siente miedo al volver a casa sola de noche”. ABC.es https://www.abc.es/familia/ mujeres/abci-83-por-ciento-mujeres-espanolas-siente-miedo-volver-casa-sola-noche-201912070142_noticia.html

${ }^{16}$ El Síndrome de Agresión a la Mujer es definido por los doctores Lorente como: "Todas aquellas agresiones sufridas por la mujer como consecuencia de los condicionantes socioculturales que actúan sobre el género masculino y femenino, situándola en una posición de subordinación al hombre, y manifestadas en los tres ámbitos básicos de relación de la persona, maltrato en el medio familiar, agresión sexual en la vida en sociedad y acoso en el medio laboral" (Lorente Acosta, 1999). 


\section{Conclusiones y directrices futuras}

Llegados a este punto, podemos concluir que la Ley 1/2004 de Medidas de Protección Integral contra la Violencia de Género ha sentado un importante precedente en la lucha contra la violencia machista en nuestro país, acompañada de diversos instrumentos jurídicos y voluntad política de cumplimiento. No obstante, los resultados y el tiempo transcurrido tras su entrada en vigor permiten considerarla una norma insuficiente que requiere de un mayor número de iniciativas y acciones de cara a atajar este problema prioritario para la sociedad española.

Es por ello que proponemos:

1. La ampliación del estatuto de la víctima de violencia de género a todos aquellos casos y contextos en los que se ejerza violencia en todas sus formas contra la mujer por el simple hecho de ser mujer, no únicamente en el ámbito de la pareja.

2. La expansión real, efectiva y completa, a su vez, del estatuto de la víctima a los hijos de la madre y mujer maltratada, como prevención al contagio generacional de la violencia de género.

3. La consideración de maltrato económico al impago y desatención de las obligaciones económicas del padre y/o esposo para evitar culpabilizar a las víctimas condenándolas a la precariedad, además de eludir la barrera de la dependencia económica como freno a la denuncia y separación del maltratador.

4. La refundición de los tipos penales de agresión y abuso sexual en una única figura jurídica que considere todo acto sexual sin consentimiento una violación, sin necesidad de mediar violencia o intimidación para enmarcarlo en esta categoría garantizando el cumplimiento íntegro del Convenio de Estambul.

5. La definición como delito de lesa humanidad a la trata de seres humanos para evitar la prescripción y favorecer así su investigación y enjuiciamiento, sumando la punición con penas privativas de libertad a los clientes de prostitución y la categoría de víctima de violencia de género para las mujeres prostituidas.

6. La creación de un registro nacional centralizado de víctimas de MGF en España, así como de población vulnerable en riesgo de sufrir esta práctica para prevenir su comisión.

7. Por último, la inclusión mediante reforma en el artículo 9.2 CE de la lucha contra la violencia de género como obligación de los poderes públicos para garantizar mediante su constitucionalización una mayor eficacia en la consecución de los objetivos de igualdad.

Esperamos que la actividad de gobierno en los años venideros para España continúe la labor en igualdad que viene realizándose hasta el presente, y es por ello que confiamos en el avance contra la violencia de género y la asunción de iniciativas como las aquí propuestas, que permitan atajar la lucha y tender puentes entre las instituciones y el movimiento feminista, para conseguir el objetivo de cero víctimas mortales al año y acabar con 
el machismo en todas sus formas en un futuro cercano. En este sentido y con la finalidad de ser un referente en la lucha contra la violencia de género, la escucha ciudadana a las reivindicaciones y demandas sociales es clave en la evitación de demoras injustificadas a la ampliación de las garantías de los derechos humanos de las mujeres, por lo que el diálogo entre los poderes públicos y el feminismo ha de marcar la agenda de gobierno en el futuro como requisito esencial para erradicar la violencia de género.

\section{Bibliografía}

ACALE SÁNCHEZ, M. (2020). "El consentimiento de la víctima: piedra angular en los delitos sexuales”, en Alapont, L. y Gónzalez Cussac (Dir.) Estudios jurídicos en memoria de la Profesora Doctora Elena Górriz Royo, Valencia: Tirant lo Blanch, pp. 35-58.

ALBERDI ALONSO, I. (2000). Las mujeres jóvenes en España. Fundación "la Caixa".

AMORÓS, C. (Coord.) (1994). Historia de la teoría feminista. Instituto de investigaciones feministas.

BAENA GARRIDO, M. (6 de febrero de 2020). En España hay 18.000 niñas en riesgo de ser mutiladas. La Vanguardia. Disponible en: https://www.lavanguardia.com/vida/ 20200206/473306966791/en-espana-hay-18000-ninas-en-riesgo-de-ser-mutiladas.html.

BERBÉL, S. (2004). Sobre sexo, género y mujeres. https://www.Mujeresenred.net.

BERISTAIN IPIÑA, A. (2000). Victimología: nueve palabras clave, Valencia: Tirant lo Blanch.

BURGUÉS, A., OLIVER, E., REDONDO, G. y SERRANO, M.Á. (2006). Investigaciones Mundiales sobre Violencia de Género en la Universidad. Convergencia con Europa y cambio en la universidad: XI Conferencia de Sociología de la Educación: Santander, 22, 23, y 24 de septiembre de 2006 [i.e. 2005] / coord. por Marta García Lastra, Adelina Calvo Salvador, José Manuel Osoro Sierra, Susana Rojas Pernía, 2006, ISBN 84-96147-77-0, págs. 130-131

CÓDIGO DE VIOLENCIA DE GÉNERO Y DOMÉSTICA. Boletín Oficial del Estado, Dirección General de la Policía, 19 de febrero de 2020. pp. 1-1200.

CONSEJO DE EUROPA (11 de mayo de 2011). Convenio del Consejo de Europa sobre prevención y lucha contra la violencia contra las mujeres y la violencia doméstica. Estambul. Disponible en: https://www.boe.es/diario_boe/txt.php?id=BOE-A-2014-5947

CONSEJO DE EUROPA. Convenio del Consejo de Europa sobre prevención y lucha contra la violencia contra las mujeres y la violencia doméstica. Boletín Oficial del Estado. "BOE" Núm. 137, de 6 de junio de 2014, páginas 42946 a 42976 (31 págs.). Disponible en: https://www.boe.es/eli/es/ai/2011/05/11/(1)

CONSTITUCIÓN ESPAÑOLA. Boletín Oficial del Estado, 29 de diciembre de 1978, núm. 311, pp. 29313 a 29424.

DE MIGUEL ÁLVAREZ, A. (2008). Feminismo y juventud en las sociedades formalmente igualitarias. Revista de Estudios de Juventud, no 83, 2008. Disponible en: https:// www.mujeresenred.net. 
DELEGACIÓN DEL GOBIERNO PARA LA VIOLENCIA DE GÉNERO (2019). Guía del Sistema de Acción y Coordinación en Casos de Violencia de Género en España. Julio de 2019, pp. 1 a 38. Disponible en: https://violenciagenero.igualdad.gob.es/informacionUtil/ guia/home.htm

DELEGACIÓN DEL GOBIERNO PARA LA VIOLENCIA DE GÉNERO (2020). La mutilación genital femenina en España. Fundación Wassu-UAB. Ministerio de Igualdad. Disponible en: https://violenciagenero.igualdad.gob.es/violenciaEnCifras/estudios/investigaciones/2020/estudio_mgf.htm

DELEGACIÓN DEL GOBIERNO PARA LA VIOLENCIA DE GÉNERO. (2020). La violencia sobre la mujer en el ámbito internacional. Disponible en: https://violenciagenero. igualdad.gob.es/marcoInternacional/ambitoInternacional/home.htm

DÍEZ GUTIÉRREZ, E. J. (2009). Prostitución y violencia de género. Nómadas. Critical Journal of Social and Juridical Sciences, 24(4), [fecha de Consulta 17 de Enero de 2021]. ISSN: 15786730. Disponible en: https://www.redalyc.org/articulo.oa?id=181/18112178023.

España. Ley Orgánica 1/2004, de 28 de diciembre, de Medidas de Protección Integral contra la Violencia de Género. Boletín Oficial del Estado. “BOE” Núm. 313, de 29/12/2004. Entrada en vigor: 28 de enero de 2015. Disponible en:

España. Ley Orgánica 10/1995, de 23 de noviembre, del Código Penal. Boletín Oficial del Estado. “BOE” núm. 281, de 24/11/1995. Entrada en vigor: 24/05/1996. Disponible en: https://www.boe.es/buscar/act.php?id=BOE-A-1995-25444.

España. Proyecto de Ley Integral, de 27 de mayo de 2011, para la Igualdad de Trato y la No Discriminación. Boletín Oficial de las Cortes Generales. “BOCG” Núm. 130-1, de 10 de junio de 2011. Disponible en: https://www.lamoncloa.gob.es/consejodeministros/ paginas/enlaces/270511ProyectoLeyIgualdadTrato.aspx.

FALUDI, S. (1991). Reacción. La guerra no declarada contra la mujer moderna. Anagrama.

FONDO DE POBLACIONES DE LAS NACIONES UNIDAS (UNFPA). (2020). Estado de la población mundial. Disponible en: https://www.unfpa.org/es/estado-de-lapoblacio\%CC\%81n-mundial-2019.

FUNDACIÓN SCELLES (2019). Sexual Explotation. New Challenges, New Awnsers. $5^{\text {th }}$ Global Report. Disponible en: https://www.globalprostitutionreport.org.

HERNÁNDEZ VELASCO, I. (4 de febrero de 2019). España, tercer país del mundo en demanda de prostitución. El Mundo. Disponible en: https://www.elmundo.es/espana/ 2019/02/04/5c588ed421efa079228b45a5.html.

INSTITUTO NACIONAL DE ESTADÍSTICA (2020). Condenados por delitos sexuales. Delitos sexuales según nacionalidad. INE.

JÓNASDÓTTIR, A. G. (1993). El poder del amor: ¿Le importa el sexo a la democracia? Madrid: Cátedra.

KOHAN, M. (16 de octubre de 2017). Principal causa de la pobreza: ser mujer. Público.es. Disponible en: https://www.publico.es/sociedad/feminizacion-pobreza-principalcausa-pobreza-mujer.html.

LERNER, G. (1986). La creación del patriarcado, Crítica.

LORENTE ACOSTA, M. (2004). El Rompecabezas: Anatomía del maltratador. Ares y Mares. 
LORENTE ACOSTA, M. y LORENTE ACOSTA, J. A. (1999). Agresión a la mujer: maltrato violación y acoso. Comares.

MARÍN DE ESPINOSA CEBALLOS, E. B. (2017). El marco normativo de la violencia de género: un estudio de derecho comparado acerca de las leyes de segunda generación y de la ley integral española. Revista de Derecho penal y Criminología, 3. a Época, n.o 17 (enero de 2017), págs. 93-126

MILLET, K. (2010). Política Sexual. Cátedra.

MILLET, K. (2019). Viaje al manicomio. Seix Barrial.

ONU, ONU Mujeres (Entidad de la ONU para la Igualdad de género y el Empoderamiento de la Mujer), 2020. Informe Anual 2019-2020 de ONU Mujeres, UN Entity for Gender Equality and the Empowerment of Women (UNWOMEN), UN Women Annual Report 2016-2017, 2017, available at: https://www.refworld.org/docid/5a1bed9a4. html. [accessed 8 December 2020]

PAZOS MORÁN, M. (2017). Apuntes para una economía política feminista. Ekonomiaz N. 91, 1. ${ }^{\mathrm{o}}$ semestre, 2017

PÉREZ DEL CAMPO NORIEGA., A. M. (1995). Una cuestión incomprendida: El maltrato a la mujer. horas y HORAS.

REDACCIÓN (23 de septiembre de 2016). Las cifras de explotación sexual en España: 40.000 mujeres la sufren. ElEconomista.es. Consultar en: https://ecodiario.eleconomista.es/sociedad/noticias/7845621/09/16/Las-cifras-de-la-explotacion-sexualen-Espana-40000-mujeres-la-sufren-.html

RODRÍGUEZ RODRÍGUEZ, E. (2008). La regulación de la igualdad entre hombres y mujeres en la normativa laboral de los países nórdicos. Aequalitas: Revista jurídica de igualdad de oportunidades entre mujeres y hombres, ISSN 1575-3379, № 23, 2008, págs. 6-15

S.F. (10/12/2019). El 83\% de las mujeres españolas siente miedo al volver a casa sola de noche. ABC.es. Disponible en: https://www.abc.es/familia/mujeres/abci-83-porciento-mujeres-espanolas-siente-miedo-volver-casa-sola-noche-201912070142_ noticia.html.

SAHUQUILLO, M. (21 de abril de 2016). Prohibido pagar por sexo en Suecia, Francia y otros seis países. ElPaís.com Disponible en: https://elpais.com/internacional/2016/04/07/actualidad/1460050306_463588.html.

SALAM, R. (2009). La muerte del macho. FP: Foreign Policy Edición Española, ISSN 16971515, №. 34 (agosto-septiembre), 2009, págs. 30-36.

SENTENCIA DEL TRIBUNAL SUPREMO 239/2021, de 17 de marzo de 2021.

TAMPEP. (2009). Sex work in Europe: a mapping of the prostitution scene in 25 european countries. TAMPEP International Foundation.

TORRES DÍAZ, M. C. (2013). La fundamentalidad del derecho a una vida libre de violencia de género: la necesidad de un marco jurídico conceptual/despatriarcalizador inserto en el texto constitucional. Universidad de Alicante. Departamento de Estudios Jurídicos del Estado.

UNICEF (2016). Female Genital Mutilation/Cutting: A Global Concern, Nueva York. Disponible en:_https://www.FGMC_2016_brochure_final_UNICEF_SPREAD.pdf 
UNODC (2010). The Globalization of Crime: A Transnational Organized Crime Threat Assessment. Publicación de las Naciones Unidas. Disponible en: http://www.unodc. org/documents/data-and analysis/tocta/TOCTA_Report_2010_low_res.pdf.

VALCÁRCEL, A. (2004). La política de las mujeres. Cátedra. 